\section{How physical exercise changes rat myotendinous junctions: an ultrastructural study}

\author{
D. Curzi, ${ }^{1}$ S. Salucci, ${ }^{1}$ M. Marini, ${ }^{2}$ \\ F. Esposito, ${ }^{3}$ L. Agnello, ${ }^{4}$ A. Veicsteinas, ${ }^{4}$ \\ S. Burattini, ${ }^{1}$ E. Falcieri ${ }^{1,5}$ \\ 'DiSTeVA, University of Urbino \\ "Carlo Bo"; 2Department of Histology, \\ Embryology and Applied Biology, \\ University of Bologna; ${ }^{3}$ Department \\ of Sport, Nutrition and Health Sciences, \\ University of Milano; ${ }^{4}$ Center of Sport \\ Medicine, Don Gnocchi Foundation,

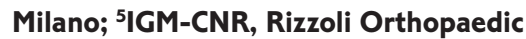 \\ Institute, Bologna, Italy
}

\section{Abstract}

Myotendinous junctions (MTJ) can be easily injured by overloading or trauma, and exercise training may be a way of increasing their resistance to mechanical stress. To this end, we examined herein the morphological changes induced by moderate exercise training in the MTJ of extensor digitorum longus (EDL) and gastrocnemius muscles in rats. Twelve Sprague-Dawley rats were used in this investigation. Six of them were trained to run on a treadmill for $1 \mathrm{~h} /$ day, 3 days/week over 10 weeks in order for them to achieve a running rate of 25 $\mathrm{m} / \mathrm{min}$ at the end of the training period. Six agematched sedentary rats were used as controls. The rats were sacrificed $24 \mathrm{~h}$ after the final training session, and the EDL and the gastrocnemium were excised; the MTJ were then prepared and observed with electron microscopy. Digitation branching was evaluated by counting the bifurcations in the MTJ protrusions. Our observations indicate that exercise does indeed induce changes in MTJ morphology. In both muscles the number of bifurcated interdigitations increased significantly, as well as, in gastrocnemius, the branching of the finger-like processes. It was demonstrated that the MTJ is able to adapt to an increase in tensile force by enlarging the muscle-tendon contact area and, consequently, mechanical resistance.

\section{Introduction}

The myotendinous junction (MTJ) is a highly specialized and architecturally complex structure. It is located at the extremities of skeletal muscle fibers where myofibrils end at the muscle cell membrane and make contact with the tendon fibers that are located in their proximity. ${ }^{1,2}$ The MTJ is also the major site of force transmission from myofibrils across the muscle cell membrane to the extracellular matrix (ECM). ${ }^{3}$ At the MTJ level, the proximal extremity of the tendon forms finger-like processes that penetrate into the muscle mass and thus increase the contact area between muscle and tendon. ${ }^{4}$ An interdigitated profile indicates separation between striated muscle and fibrous connective tissue, where a sort of muscle-tendon crosstalk occurs. ${ }^{5}$ Force transmission to the extracellular matrix is thought to be the result of the combined action of two groups of proteins which bridge across the membrane. The first group is initiated on the muscle cell side with the binding of actin to dystrophin. This in turn binds to $\beta$-dystroglycan. At the extracellular site, $\sigma$-dystroglycan is linked to ECM laminin-2 by means of $\alpha$-dystroglycan. The sarcoglycan complex may function in stabilizing the entire complex. Dystrophin is located at the inner surface of the cell membrane and is capable of binding to muscle cell membrane proteins. ${ }^{6}$ The second group of proteins initiates with the binding of actin to talin, which in turn links vinculin. Vinculin is associated with the $\alpha 7 \beta 1$ integrin, which binds to ECM collagen and laminin-211. ${ }^{7-9}$ $\alpha 7 \beta 1$ is the predominant integrin in adult skeletal muscle. Integrins play important roles in skeletal muscle development and function. In fact, the ablation of the murine $\beta 1$ integrin subunit gene, which leads to the loss of all $\alpha \beta 1$ integrins, causes defects in myoblast fusion and sarcomere assembly. ${ }^{10}$ The $\alpha 7$ subunit determines the specificity of ligand binding to laminin in the basal lamina surrounding individual muscle fibers, whereas the $\beta 1$ subunit participates in the linkage with actin via several subsarcolemmal proteins, including $\alpha$ actinin, talin, vinculin, paxillin and tensin. ${ }^{11}$ Mutations in the gene that encodes the $\alpha 7$ integrin subunit cause congenital myopathy in humans, ${ }^{12,13}$ while the genetic ablation of either the $\alpha 5$ or $\alpha 7$ integrin subunit causes muscular dystrophy in mice. ${ }^{14}$ Moreover, the inactivation of the $\alpha 7$ integrin subunit leads to the detachment of MTJs from the ECM. ${ }^{7,15,16}$ The transgenic expression of the $\alpha 7 \beta 1$ integrin in the dystrophic mdx/utr-/- mouse decreases development of muscular dystrophy and enhances longevity. One hallmark of the integrin-mediated alleviation of muscular dystrophy in the mdx/utr-/- background is the restoration of MTJ integrity. Milner and Kaufman demonstrated that the $\alpha 7 \beta 1$ integrin does not alleviate disease in a mouse model with limb girdle muscular dystrophy type $2 \mathrm{~F}$ and MTJ from normal and delta sgc-null mice are indistinguishable. These results suggest the important influence of MTJ integrity on the severity of muscular dystrophy. ${ }^{17}$

In skeletal muscle, $\beta 1$ integrins have been
Correspondence: Prof. Elisabetta Falcieri, DiSTeVA, Urbino University "Carlo Bo", via Ca' le Suore, Urbino, Italy.

Tel. +39.0722 .304317 - Fax: +39.0722 .304244 .

E-mail: elisabetta.falcieri@uniurb.it

Key words: myotendinous junctions, ultrastructure, tension, training, exercise, skeletal muscle, tendon.

Acknowledgments: the authors would like to thank Dr. Michela Battistelli, Dr. Valentina Baldassarri, Dr. Federico Bastianelli and Mr. Aurelio Valmori for technical help. They are also indebted to Prof. Marco B. Rocchi and Dr. Stefano Ciuffoli for statistical evaluations.

The work was supported by Urbino University and the Ministry of Education, University and Research (PRIN 2009).

Contributions: SB and EF contributed equally to the manuscript.

Received for publication: 19 October 2011. Accepted for publication: 2 March 2012.

This work is licensed under a Creative Commons Attribution NonCommercial 3.0 License (CC BYNC 3.0).

@C Copyright D. Curzi et al., 2012

Licensee PAGEPress, Italy

European Journal of Histochemistry 2012; 56:e19 doi:10.4081/ejh.2012.e19

reported to be localized in costamers and MTJs, where they establish a bridge between the cytoskeleton and the ECM. ${ }^{18-21}$ These connections are important for transmitting mechanical forces and maintaining skeletal muscle fibers. The ECM plays a key role in force transmission and tissue structure maintenance in tendons, ligaments, cartilage, bone and muscle. Its turnover is influenced by physical activity, and both collagen synthesis and metalloprotease activity increase with mechanical loading. ${ }^{22}$ ECM proteins in the tendon, especially collagen type I, as well as tenocytes and their cellular protrusions, are predominantly oriented along the direction of applied force. Collagen type I is the main ECM component, comprising more than $60 \%$ of the tendon dry weight. The structure and composition of the ECM in tendons is able to adapt to changes in mechanical loading that are correlated to muscle contraction..$^{23}$ MTJ structural organization is influenced by both the development of muscle and tendon tissues and their interaction. Indeed, the ability to generate the force that is acquired by muscles during the final few weeks of foetal, and the first few weeks of neonatal growth is of critical importance for the formation of functional MTJ structures. $^{24}$

In recent years, morpho-functional changes in the MTJ have been described as occurring in rats exposed to eccentric strength training or running exercise. In particular, it has been 
shown that both muscle architecture and tendon properties are modulated by exercise training: muscle thickness and the fascicle angle increase significantly at rest and during contraction, whereas fascicle length increases at rest and does not change during contraction. Furthermore, it has also been demonstrated that gastrocnemius tendon stiffness increases significantly, suggesting that muscle architecture and tendon mechanical properties are differently affected by strength training. ${ }^{25}$ Eccentric contractions can also trigger intense protein synthesis activity at the MTJ, which is probably related to the myofibrillogenesis that is associated with MTJ remodeling. ${ }^{26}$ Another study reported ultrastructural changes in the finger-like process of the MTJ in rats trained to run. ${ }^{27}$ Unlike earlier work, in this study EDL muscle was investigated by its reduced involvement during training compared to the tibialis anterior. The aim of our research was to examine exercise-induced ultrastructural changes in the MTJ of EDL and gastrocnemius muscles in rats.

\section{Materials and Methods}

\section{Animals and training protocol}

Twelve male albino Sprague-Dawley rats aged eight weeks were placed in individual cages and fed a standard diet without limitations. Room temperature was kept at $21 \pm 2^{\circ} \mathrm{C}$ and $12 \mathrm{~h}$ of light was automatically alternated with $12 \mathrm{~h}$ of dark. After one week of acclimatization, 6 rats were randomly chosen to run on a six-lane rodent treadmill three times a week at a $10 \%$ grade slope. The time and speed were gradually increased over five weeks to reach 1 $\mathrm{h}$ a day for $25 \mathrm{~m} / \mathrm{min}$. These parameters were then maintained for a further five weeks of training. The level of aerobic training thus achieved corresponded to approximately $60 \%$ $V \mathrm{O}_{2 \max }{ }^{28}$ Control animals $(\mathrm{n}=6)$ were placed on a non-moving treadmill during the training sessions. At the end of the 10-week training period, both the control and the trained animals were sacrificed. ${ }^{29}$ All the experimental evaluations were carried out on all animals of each experimental group.

Animal handling, the training protocol and the mode of killing were approved by the Ethical Committee on the Use of Laboratory Animals of the Health Authority of Milan (Italy) according to the 86/609/CEE guidelines (Protocol \#3407, 24/09/2007). The training also complied with the American Physiological Society guidelines for exercising rodents on treadmills (American Physiological Society 2006). The rats were periodically examined by a veterinarian. Their food consumption and
Table 1. Body and hind limb skeletal muscle mass in control and trained rats, evaluated at the time of sacrifice.

\begin{tabular}{|c|c|c|c|c|c|}
\hline \multirow[t]{2}{*}{ Group } & \multicolumn{2}{|c|}{ Control $(n=6)$} & \multicolumn{2}{|c|}{ Trained (n=6) } & \multirow{2}{*}{$\begin{array}{c}t \text {-test } \\
\text { (control } v s \\
\text { trained) }\end{array}$} \\
\hline & Mean & SD & Mean & SD & \\
\hline Body mass (BM) (g) & 572.21 & 56.1 & 514.45 & 39.3 & 0.000 \\
\hline EDL mass (EM) $(\mathrm{g})^{*}$ & 0.249 & 0.033 & 0.244 & 0.023 & 0.403 \\
\hline Right EM/BM*100 & 0.044 & 0.004 & 0.047 & 0.004 & 0.003 \\
\hline Gastrocnemius mass (GM) (g)* & 3.437 & 0.436 & 3.325 & 0.311 & 0.165 \\
\hline Right GM/BM*100 & 0.596 & 0.080 & 0.641 & 0.046 & 0.025 \\
\hline
\end{tabular}

EDL, extensor digitorum longum; * the mass of the EDL and the gastrocnemius from left and right limbs was averaged.
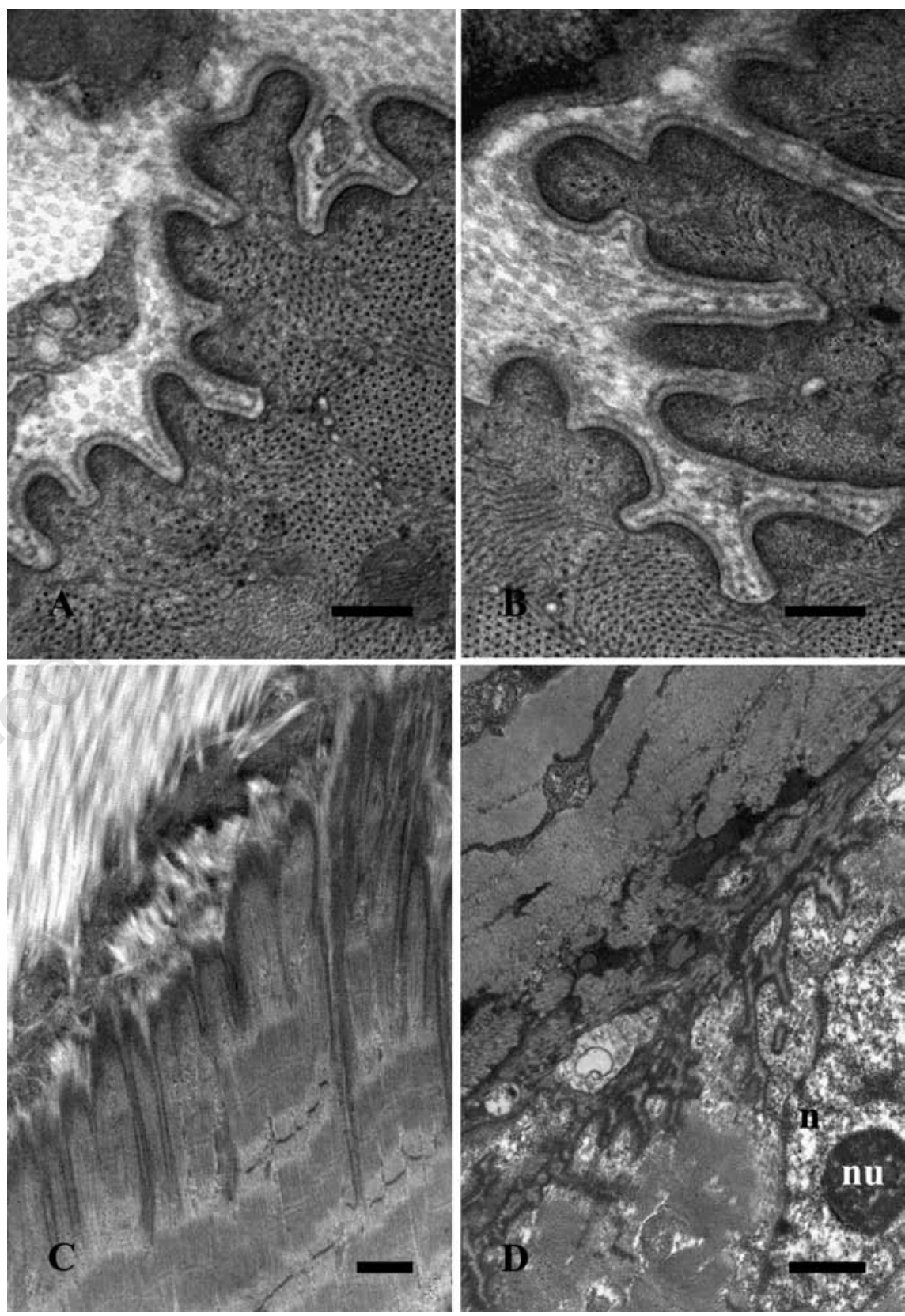

Figure 1. Extensor digitorum longum muscle electron microscope images from control $(A, C)$ and trained $(B, D)$ rats in transverse $(A, B)$ and longitudinal $(C, D)$ sections. Scale bars: A,B, $0.25 \mu \mathrm{m}$; C,D, $1 \mu \mathrm{m}$. 
body weight were evaluated three times a week, and their internal organs, which were examined by a pathologist on the day they were killed, appeared to be normal and disease-free.

\section{Light and electron microscopy}

The rats were anesthetized $(100 \mathrm{mg} / \mathrm{kg}$ i.p. heparinized sodium thiopental), weighed and then beheaded. The EDL and gastrocnemius muscles were obtained from both hind legs, and were then quickly blotted dry, freed of connective tissue and weighed on a precision scale. Muscle fragments, maintained under tension with pins, were immediately fixed with $2.5 \%$ glutaraldehyde in a $0.1 \mathrm{M}$ phosphate buffer for 3-6 h and quickly minced into smaller $\left(<1 \mathrm{~mm}^{3}\right)$ fragments. They were then postfixed with $1 \% \mathrm{OsO}_{4}$ for $1 \mathrm{~h}$ in the same buffer, dehydrated with alcohol and embedded in araldite. Semi-thin sections, stained with $1 \%$ toluidine blue in distilled water at $60^{\circ} \mathrm{C}$, were observed by light microscope. The sections were trimmed to produce a thorough longitudinal or transverse plane of the muscle fibers, allowing clear MTJ identification. Thin sections stained with uranyl acetate and lead citrate were then observed with a Philips CM10 electron microscope (TEM). ${ }^{30,31}$

\section{Morphometric analysis}

Fifty images of MTJ were evaluated from EDL and gastrocnemius muscles from both control and trained rats. The branching of the finger-like processes was analyzed in each condition. The different percentages of branched interdigitations among the samples were evaluated with the $\chi^{2}$-test. Values of $\mathrm{P}<0.001$ were regarded as statistically significant. The different means of bifurcation among the samples were evaluated with a ttest. Values of $\mathrm{P}<0.05$ were considered to be statistically significant.

\section{Results}

\section{Muscle and body weight}

To assess the effectiveness of the training protocols, the EDL and gastrocnemium muscles were individually weighed and their body mass ratio calculated. The data obtained are set out in Table 1. As already reported, body mass was significantly lower in the trained rats than in the controls, but the EDL and the gastrocnemius mass did not significantly differ in terms of absolute values between the two groups. However, the muscle mass/body mass ratio was greater in the trained rats for both muscles. $^{32}$
Table 2. Distribution of principal protrusions according to bifurcation number.

\begin{tabular}{lcccc}
$\begin{array}{l}\text { Bifurcation } \\
\text { number }\end{array}$ & $\begin{array}{c}\text { Control } \\
\text { EDL }\end{array}$ & $\begin{array}{c}\text { Trained } \\
\text { EDL }\end{array}$ & $\begin{array}{c}\text { Control } \\
\text { gastrocnemius }\end{array}$ & $\begin{array}{c}\text { Trained } \\
\text { gastrocnemius }\end{array}$ \\
0 & 47 & 31 & 37 & 18 \\
1 & 2 & 16 & 12 & 16 \\
\hline 2 & 1 & 3 & 1 & 6 \\
3 & 0 & 0 & 0 & 5 \\
\hline 4 & 0 & 0 & 0 & 2 \\
5 & 0 & 0 & 0 & 2 \\
\hline 6 & 0 & 0 & 0 & 0 \\
7 & 0 & 0 & 0 & 1 \\
\hline
\end{tabular}

EDL, extensor digitorum longum.
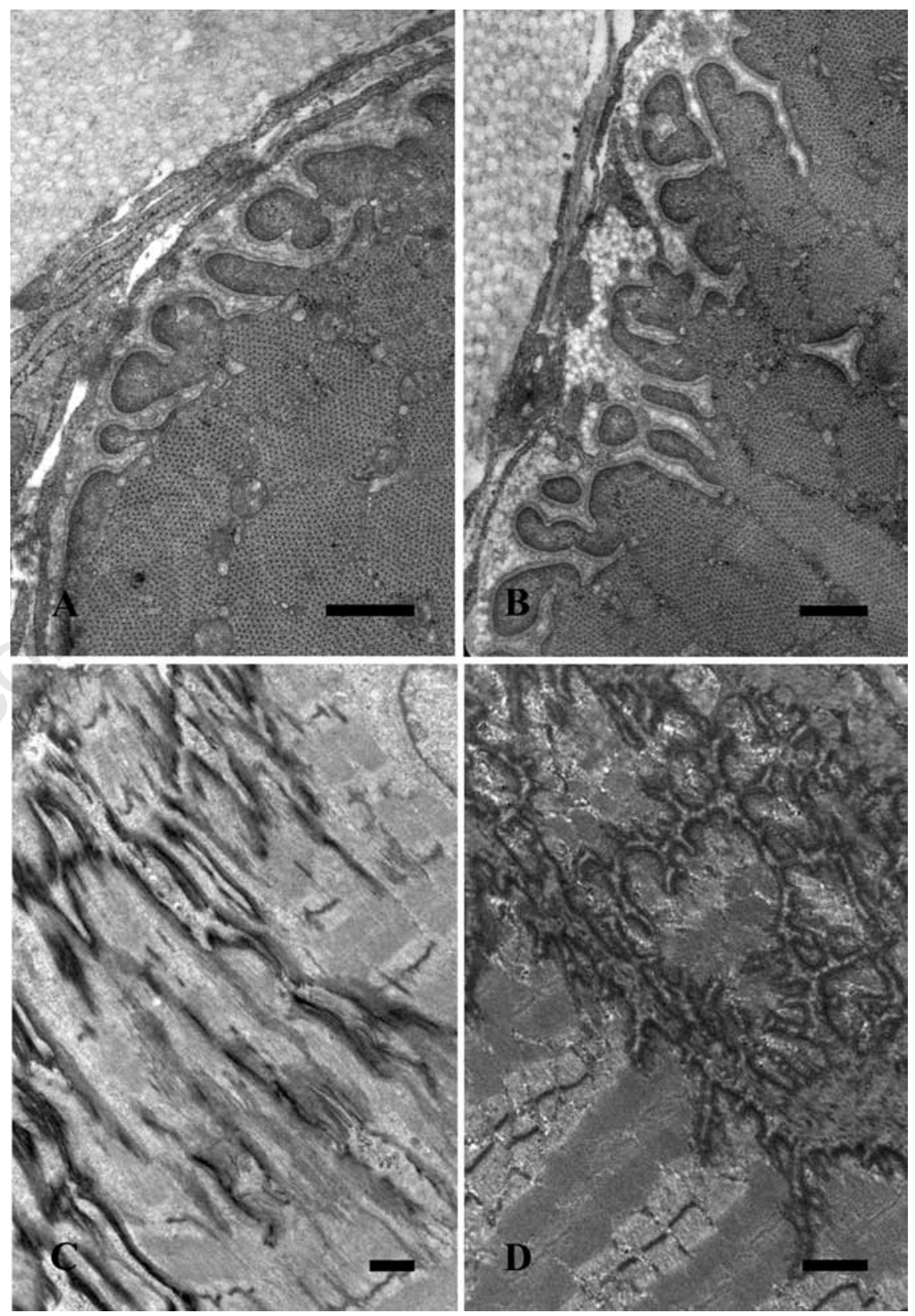

Figure 2. Gastrocnemius muscle electron microscope images from control $(\mathrm{A}, \mathrm{C})$ and trained $(B, D)$ rats in transverse $(A, B)$ and longitudinal $(C, D)$ sections. Scale bars: $A, B, 0.5$ $\mu \mathrm{m} ; \mathrm{C}, \mathrm{D}, \mathbf{1} \mu \mathrm{m}$. 


\section{Morphology}

Figure 1 shows representative images of the TEM ultrastructural study of the EDL muscle from the control $(A, C)$ and the trained $(B, D)$ rats, in both transverse $(A, B)$ and longitudinal (C,D) sections. The EDL MTJs from the control rats are characterized by rounded protrusions that are surrounded by a uniform basal membrane, which separates muscle from tendon tissue (Figure 1A). The EDL MTJs from the trained rats, meanwhile, clearly display more branching of the finger-like processes (Figure 1B). Longitudinal sections reveal the presence of long, bifurcation-free, digitations, penetrating in the sarcolemma in the control muscle (Figure 1C). These digitations not only markedly increase in number in the trained muscle (Figure 1D), but also give rise to a sort of meshwork. A nucleus (n) with a central
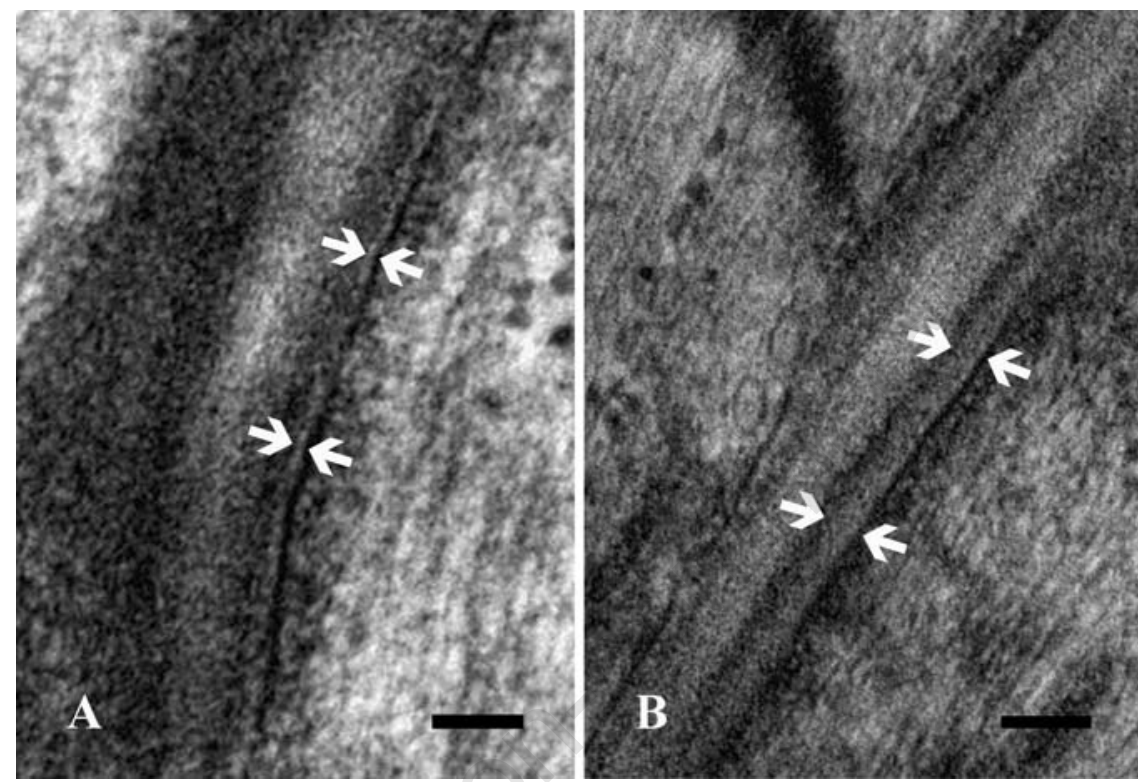

Figure 3. Higher magnification details of control (A) and trained (B) gastrocnemius muscle myotendinous junctions. The muscle basal lamina, identified by the opposite arrows, appears thicker in trained than in control rats. Scale bars: $0.1 \mu \mathrm{m}$.
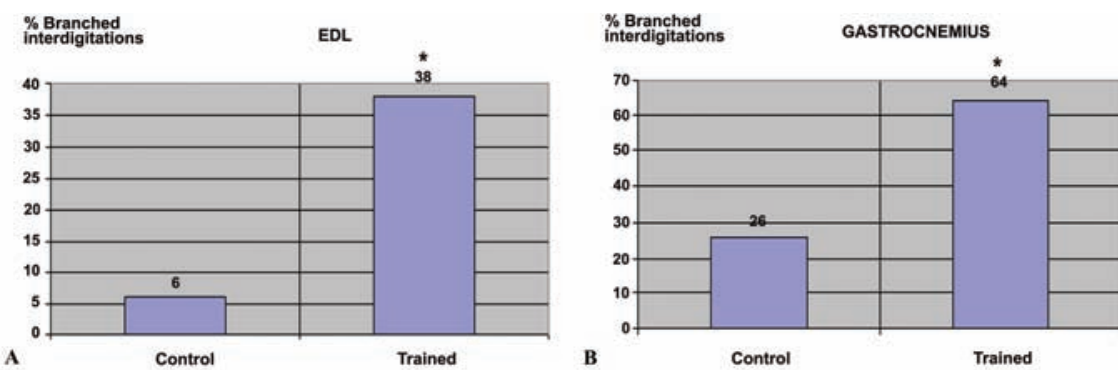

Figure 4. Percentage study of branched principal interdigitations, respectively in the extensor digitorum longum (A) and gastrocnemius myotendinous junctions (B). ${ }^{*} \mathrm{P}<\mathbf{0 . 0 0 1}$. nucleolus (nu) can also be observed in the muscle tissue.

Figure 2 sets out representative TEM images of gastrocnemius muscle MTJs from control $(A, C)$ and the trained $(B, D)$ rats in ( sarcolemmal dense masses and a homogeneous basal membrane. Cross-sectioned collagen fibrils are clearly present. After training (B), the muscle digitations appear to have Longitudinal sections of the control muscle reveal long, bifurcation-free, projections, digitation branching and fusing, appears in the trained muscle (D). At higher magnification (Figure 3), the MTJs from the gastrocnemius muscle display digitations with a thicker characterized by myofilaments ending in subincreased both in length and number. ly in the trained group. The difference between
lativethe control and the trained group in respect of the gastrocnemius was thus statistically significant $(\mathrm{P}<0.05)$.

\section{Discussion}

Force transmission between muscles and tendons occurs through the MTJ, which is a specialized structure with peculiar morphological and molecular features. At the MTJ level, the muscle enlarges the contact area by forming finger-like interdigitations of the basement membrane zone at the junction in order to overcome the mechanical strain across the cell membrane. . $23,33^{2,3}$

The basement membrane is a thin layer of a specialized ECM that surrounds skeletal muscle fibers. ${ }^{34}$ Genetic studies on patients and animal models with muscular dystrophy have demonstrated the importance of the basement membrane for the maintenance of muscle

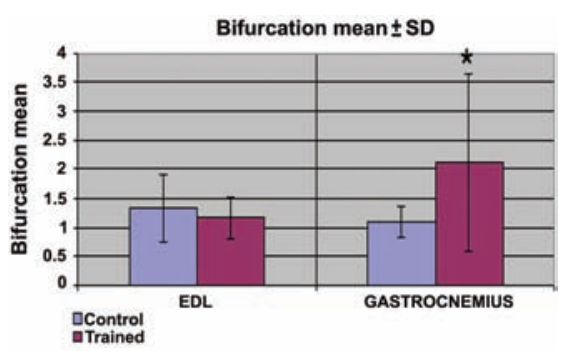

Figure 5. Study of bifurcation means of principal interdigitations. ${ }^{*} \mathbf{P}<0.05$. 
integrity, as well as for the promotion of myogenesis and muscle development. ${ }^{35}$ The major structural features of the MTJ that are observed by electron microscopy include the extensive invaginations of the sarcolemma and the areas of increased electron density in the subsarcolemmal area to which actin filaments from the terminal sarcomere are attached. ${ }^{36}$ Invagination of the junctional sarcolemma is necessary to increase the membrane surface area, in particular the adhesive interface between muscle sarcolemma and tendon. ${ }^{37}$ In this study, we have observed ultrastructural changes in MTJ finger-like processes and an increase of basal lamina thickness in the hind limb muscles of trained rats. Trauma or overloading may lead to MTJ injuries. In particular, the gastrocnemius muscle is prone to strain injury due to its action across two joints and its superficial location. Gradually increasing muscle load in a nontraumatic manner by moderate exercise training may lead to the reinforcement of the MTJ, which can be viewed as a way to prevent injuries to this structure.

Several studies have dealt with the effect of exercise on skeletal muscle MTJs, in particular during post-traumatic rehabilitation. ${ }^{38,39}$ Zamora and Marini caused the overloading of rat plantaris muscles by the aseptic ablation of the synergists. They then described enhanced collagen synthesis occurring at the MTJ and, interestingly, the appearance of activated tendon fibroblasts with a vescicular nucleus and prominent nucleoli that are very similar to those that we describe herein (Figure 3D). ${ }^{40}$ On the other hand, Kannus and others demonstrated that after three weeks of immobilization, the contact area between muscle cells and tendineal collagen fibers was reduced by almost 50\% in both type I and type II muscle fibers. Their basal membranes, meanwhile, were slightly thickened ${ }^{41}$ Kojima et al. examined the frequency of the branching of the MTJ finger-like processes and their direction following a 4-wk training period. ${ }^{27}$ Although there are experimental differences that do not permit a direct comparison to be made between the Kojima group's results and ours, it is noteworthy that we also observed a significant, increasing percentage of branched interdigitations in the EDL MTJs of the trained group, while the bifurcation mean between the control and the trained protrusions was not statistically significant. Moreover, it has been observed that growth, loading and mobilization lead to changes in tendon composition. Moderate exercise for several weeks led not only to an increase in total proteoglycan content, but also to qualitative changes in proteoglycan make up. ${ }^{42}$

These observations indicate that changes in the MTJs also occurred at the ultrastructural level as an adaptation to exercise-induced tension increase. Tension at the junction level is indeed lower during rest than during exercise, a condition in which it acts as a shearing force for the junction. The branching of the fingerlike processes allows the contact areas to increase in size. This leads to the enlargement of the entire tendon-muscle surface area and, therefore, a better resistance to tension. Moreover, apparent morphological changes in basal lamina components with exercise suggest a reorganization of protein architecture at the MTJ level, which can thus adapt to the shearing force, if necessary by increasing the number of muscle-tendon branches, their distribution complexity and their structure.

The present work should be viewed as the starting point for further studies, which are in progress in our laboratory. Using immunocytochemical and proteomic approaches, we plan to further characterize training-induced MTJ biochemical and structural modifications.

\section{References}

1. St Pierre BA, Tidball JG. Macrophage activation and muscle remodeling at myotendinous junctions after modifications in muscle loading. Am $\mathrm{J}$ Pathol 1994;145:1463-71.

2. Kostrominova TY, Calve S, Arruda EM, Larkin LM. Ultrastructure of myotendinous junctions in tendon-skeletal muscle constructs engineered in vitro. Histol Histopathol 2009;24:541-50.

3. Law DJ, Allen DL, Tidball JG. Talin, vinculin and DRP (utrophin) concentrations are increased at mdx myotendinous junctions following onset of necrosis. J Cell Sci 1994;107:1477-83.

4. Tidball JG. Assembly of myotendinous junctions in the chick embryo: deposition of P68 is an early event in myotendinous junction formation. Dev Biol 1994;163:44756.

5. Rodriguez-Guzman M, Montero JA, Santesteban E, Gañan Y, Macias D, Hurle JM. Tendon-muscle crosstalk controls muscle bellies morphogenesis, which is mediated by cell death and retinoic acid signaling. Dev Biol 2007;302:267-80.

6. Byers TJ, Kunkel LM, Watkins SC. The subcellular distribution of dystrophin in mouse skeletal, cardiac, and smooth muscle. J Cell Biol 1991;115:411-21.

7. Welser JV, Rooney JE, Cohen NC, Gurpur PB, Singer CA, Evans RA, et al. Myotendinous junction defects and reduced force transmission in mice that lack alpha7 integrin and utrophin. Am J Pathol 2009;175:1545-54.
8. Monti RJ, Roy RR, Hodgson JA, Edgerton VR. Transmission of forces within mammalian skeletal muscles. J Biomech 1999; 32:371-80.

9. Gawlik KI, Durbeej M. Skeletal muscle laminin and MDC1A: pathogenesis and treatment strategies. Skelet Muscle 2011; $1: 9$.

10. Schwander M, Leu M, Stumm M, Dorchies OM, Ruegg UT, Schittny J, et al. Betal integrins regulate myoblast fusion and sarcomere assembly. Dev Cell 2003;4:67385.

11. Boppart MD, Volker SE, Alexander N, Burkin DJ, Kaufman SJ. Exercise promotes alpha7 integrin gene transcription and protection of skeletal muscle. Am J Physiol Regul Integr Comp Physiol 2008;295:R1623-30.

12. Hayashi YK, Chou FL, Engvall E, Ogawa M, Matsuda C, Hirabayashi S, et al. Mutations in the integrin alpha7 gene cause congenital myopathy. Nat Genet 1998;19:94-7.

13. Oldfors A, Tajsharghi H, Darin N, Lindberg C. Myopathies associated with myosin heavy chain mutations. Acta Myol 2004; 23:90-6.

14. Mayer U. Integrins: redundant or important players in skeletal muscle? J Biol Chem 2003;278:14587-90.

15. Burkin DJ, Kaufman SJ. The alpha7betal integrin in muscle development and disease. Cell Tissue Res 1999;296:183-90.

16. Miosge N, Klenczar C, Herken R, Willem $M$, Mayer U. Organization of the myotendinous junction is dependent on the presence of alpha7betal integrin. Lab Invest 1999;79:1591-9.

17. Milner DJ, Kaufman SJ. Alpha7betal integrin does not alleviate disease in a mouse model of limb girdle muscular dystrophy type 2F. Am J Pathol 2007;170:609-19.

18. Mayer U, Saher G, Fässler R, Bornemann A, Echtermeyer F, von der Mark $\mathrm{H}$ et al. Absence of integrin alpha 7 causes a novel form of muscular dystrophy. Nat Genet $1997 ; 17: 318-323$.

19. Anastasi G, Cutroneo G, Santoro G, Arco A, Rizzo G, Trommino C et al. Integrins, muscle agrin and sarcoglycans during muscular inactivity conditions: an immunohistochemical study. Eur J Histochem 2006; 50:327-336.

20. Anastasi G, Cutroneo G, Santoro G, Arco A, Rizzo G, Bramanti P, et al. Costameric proteins in human skeletal muscle during muscular inactivity. J Anat 2008;213:28495.

21. Conti FJ, Monkley SJ, Wood MR, Critchley DR, Müller U. Talin 1 and 2 are required for myoblast fusion, sarcomere assembly and the maintenance of myotendinous junctions. Development 2009;136:3597- 
606.

22. Reich A, Maziel SS, Ashkenazi Z, Ornan EM. Involvement of matrix metalloproteinases in the growth plate response to physiological mechanical load. J Appl Physiol 2010;108:172-80.

23. Kjaer M, Magnusson P, Krogsgaard M, Boysen Møller J, Olesen J, Heinemeier K et al. Extracellular matrix adaptation of tendon and skeletal muscle to exercise. J Anat 2006;208:445-50.

24. Tozer S, Duprez D. Tendon and ligament: development, repair and disease. Birth Defects Res C Embryo Today 2005;75:22636 .

25. Duclay J, Martin A, Duclay A, Cometti G, Pousson M. Behavior of fascicles and the myotendinous junction of human medial gastrocnemius following eccentric strength training. Muscle Nerve 2009;39:819-27.

26. Frenette J, Côté $\mathrm{CH}$. Modulation of structural protein content of the myotendinous junction following eccentric contractions. Int J Sports Med 2000;21:313-20.

27. Kojima H, Sakuma E, Mabuchi Y, Mizutani J, Horiuchi 0, Wada I, et al. Ultrastructural changes at the myotendinous junction induced by exercise. J Orthop Sci 2008;13:233-9.

28. Wisløff U, Brubakk AO. Aerobic endurance training reduces bubble formation and increases survival in rats exposed to hyperbaric pressure. J Physiol 2001;537:607-11.
29. Marini M, Falcieri E, Margonato V, Treré D, Lapalombella R, di Tullio S, et al. Partial persistence of exercise-induced myocardial angiogenesis following 4-week detraining in the rat. Histochem Cell Biol 2008;129:479-87.

30. Burattini S, Ferri P, Battistelli M, Curci R, Luchetti F, Falcieri E. C2C12 murine myoblasts as a model of skeletal muscle development: morpho-functional characterization. Eur J Histochem 2004;48:22333 .

31. D'Emilio A, Biagiotti L, Burattini S, Battistelli M, Canonico B, Evangelisti C, et al. Morphological and biochemical patterns in skeletal muscle apoptosis. Histol Histopathol 2010;25:21-32.

32. Marini M, Lapalombella R, Margonato V, Ronchi R, Samaja M, Scapin C, et al. Mild exercise training, cardioprotection and stress gene profile. Eur J Appl Physiol 2007;99:503-10.

33. Wang HV, Chang LW, Brixius K, Wickström SA, Montanez E, Thievessen I, et al. Integrin-linked kinase stabilizes myotendinous junctions and protects muscle from stress-induced damage. J Cell Biol 2008;180:1037-49.

34. Sanes JR. The basement membrane/basal lamina of skeletal muscle. J Biol Chem 2003;278:12601-4.

35. Campbell KP, Stull JT. Skeletal muscle basement membrane-sarcolemmacytoskeleton interaction mini review series. J Biol Chem 2003;278:12599-600.
36. Swasdison S, Mayne R. In vitro attachment of skeletal muscle fibers to a collagen gel duplicates the structure of the myotendinous junction. Exp Cell Res 1991;193:22731.

37. Trotter JA, Hsi K, Samora A, Wofsy C. A morphometric analysis of the muscle-tendon junction. Anat Rec 1985;213:26-32.

38. Kvist M, Hurme T, Kannus P, Järvinen T, Maunu VM, Jozsa L, et al. Vascular density at the myotendinous junction of the rat gastrocnemius muscle after immobilization and remobilization. Am J Sports Med 1995;23:359-64.

39. Järvinen TA, Józsa L, Kannus P, Järvinen TL, Hurme T, Kvist M, et al. Mechanical loading regulates the expression of tenascin- $\mathrm{C}$ in the myotendinous junction and tendon but does not induce de novo synthesis in the skeletal muscle. J Cell Sci 2003;116:857-66.

40. Zamora AJ, Marini JF. Tendon and myotendinous junction in an overloaded skeletal muscle of the rat. Anat Embryol (Berl) 1988;179:89-96.

41. Kannus P, Jozsa L, Kvist M, Lehto M, Järvinen $M$. The effect of immobilization on myotendinous junction: an ultrastructural, histochemical and immunohistochemical study. Acta Physiol Scand 1992;144:387-94.

42. Hae Yoon J, Halper J. Tendon proteoglycans: biochemistry and function. J Musculoskelet Neuronal Interact 2005;5: 22-34. 